\title{
Fruiting bodies yield of oyster mushroom (Pleurotus columbinus) as affected by different portions of compost in the substrate
}

\author{
Mohamed F. Mohamed ${ }^{1} \cdot$ Emad F. S. Refaei $^{2} \cdot$ Mohamed M. A. Abdalla $^{1}$ \\ Sayed H. Abdelgalil ${ }^{3}$
}

Received: 12 December 2015/ Accepted: 20 September 2016/Published online: 29 September 2016

(c) The Author(s) 2016. This article is published with open access at Springerlink.com

\begin{abstract}
Purpose A study was conducted to assess production of Pleurotus columbinus mushroom fruiting bodies for different formulations of rice or corn straw substrates mixed at different percent portions with the corresponding composted straw.

Methods These formulations were: (1) raw straw (RS) mixed with $5 \%$ composted straw (CS), (2) RS mixed with $10 \%$ CS, (3) RS mixed with $15 \%$ CS, (4) RS mixed with $25 \%$ CS, (5) RS mixed with $50 \%$ CS, and (6) $100 \%$ RS. Composted straw (CS) was made of moistened chopped RS mixed with chicken manure and soil $(4: 1: 1, \mathrm{v} / \mathrm{v})$.

Results Data showed a magnificent impact of the substrate on oyster mushroom fruiting bodies yield and characteristics. There was a significant progressive upgrading in all parameters studied of mushroom growth and crop outcome with increasing the percentage of CS mixed with the RS substrate up to $15 \%$. Utilizing CS at $25 \%$ significantly downgraded these parameters. No mushroom growth was observed at all when cultivated in medium contained $50 \%$ CS. Instead, molds of different colors grew on that latter substrate mixture. The formulation containing $15 \% \mathrm{CS}$ distinctly gave the uppermost fruiting bodies yield, biological efficiency, earliness for pinheads formation, fruiting body cap diameter, thickness and weight and stem
\end{abstract}

Mohamed F. Mohamed

mofouad@yahoo.com

1 Department of Horticulture, Faculty of Agriculture, Assiut University, Assiut 71526, Egypt

2 Horticulture Research Institute, Agriculture Research Center, Giza, Egypt

3 Central Laboratory for Organic Farming, Agriculture Research Center, Giza, Egypt diameter, length and weight. Up to $80 \%$ increase in fruiting bodies crop outcome relative to sole RS was detected.

Conclusions This study suggests that composted straw substrates hold a great promise for the development of Pleurotus mushroom production industry.

Keywords Fruiting bodies · Edible fungi - Lignocellulosic wastes · Macrofungi - Pleurotus columbinus · Primary decomposer

\section{Introduction}

The cultivated Pleurotus mushrooms include a number of different species: Pleurotus ostreatus, Pleurotus sajorcaju, Pleurotus columbinus, Pleurotus cystidus, Pleurotus citrinopileatus, and Pleurotus flabellatus. Pleurotus mushrooms are widespread in the temperate zones representing the third largest groups of the cultivated edible mushrooms in the world (Mendez et al. 2005; Sarangi et al. 2006; Sher et al. 2010). China is the major producer of oyster mushroom. The production of this mushroom species is estimated to be $25 \%$ of the total world production of cultivated mushrooms. The Pleurotus mushrooms are nutritionally and gastronomically important (Sarangi et al. 2006; Valverde et al. 2015). In addition, mushroom spent substrate can be potentially utilized in crop organic production (Lopes et al. 2015).

Oyster mushroom production using various sources of agricultural wastes has received a renewed interest of researchers (Jeznabadi et al. 2016; Mohamed et al. 2012). Furthermore, the appropriate preparation of the substrate is crucial for the production of maximized yield of Pleurotus mushrooms (Choi et al. 2009; Obodai and Johnson 2002; 
Soliman 2011). Pleurotus mushroom species, unlike button mushroom (Agaricus bisporus), are primary decomposers (Mohamed et al. 2014). They can break down and absorb the components of substrate materials that have not been degraded. Therefore, cultivation of Pleurotus mushrooms is considered to be a simple, low cost, and environmentally friendly technology for the utilization of rural and agroindustrial residues in the developing countries (Kirbag and Akyüz 2008; Mohamed et al. 2011; Zhang, et al. 2014). However, it has been found that fermented substrate materials produce high yield and quality fruiting bodies (Choi 2004). As shown by Obodai and Johnson (2002), composted Triplochiton scleroxylon sawdust mixed with other substrates significantly increased the yield of P. ostreatus.

Substrate materials in nature have microorganisms attached to their surfaces. The initial microorganisms that exist come mainly from the soil. Activity of these microorganisms is suppressed on dry material. When such organic materials are moistened, microorganisms can propagate and the nutritive substances of the substrate are accumulated in form of protein and other useful compounds. Thus, fermentation during composting can be defined as the conversion of the nutrients of substrates by microorganisms into other important compounds (Choi 2004). By pasteurization of substrate, most of contaminating microorganisms are killed and protein can be utilized by growing mushroom. This study presents an assessment of $P$. columbinus mushroom productivity when cultivated on substrate formulations of composted rice (Oryza sativa L.) or corn (Zea mays L.) straws mixed at different portions with raw straw.

\section{Materials and methods}

This study was conducted in the mushroom research and production laboratory, Department of Horticulture, Faculty of Agriculture, Assiut University. Production of Pleurotus columbinus mushroom fruiting bodies was assessed for different formulations of mixed composted straw with raw straw substrate $(\mathrm{w} / \mathrm{w})$. The compost was made of moistened chopped raw rice (Oryza sativa L.) straw or corn (Zea mays L.) straw mixed with chicken manure and soil (4:1:1, $\mathrm{v} / \mathrm{v})$. The soil was clay loam and was collected from the top $20 \mathrm{~cm}$ in the Vegetable Crop Research Farm, Faculty of Agriculture, Assiut University, Assiut city. Soil was added to enrich the materials with biodegrading mesophile microorganisms. Raw straw was used as a carbon source for the biodegrading mesophile microorganisms. Detailed procedure for compost preparation is described elsewhere here under general procedure. Spawn of Pleurotus columbinus mushroom used in this study was obtained from Agricultural Research Center, Food Technology Research Institute, Giza.

\section{Pilot assessment and particular experiment designation}

In a preliminary assessment, five treatments were studied. These were: (1) $100 \%$ raw straw (RS) (control), (2) $75 \%$ RS mixed with $25 \%$ compost (CS), (3) $50 \%$ RS mixed with $50 \%$ CS, (4) $25 \%$ RS mixed with $75 \%$ CS, and (5) $100 \% \mathrm{CS}$. Based on this preliminary assessment, the treatments of the substrate formulations were modified to be: (1) RS mixed with $5 \% \mathrm{CS}$, (2) RS mixed with $10 \%$ CS, (3) RS mixed with $15 \%$ CS, (4) RS mixed with $25 \%$ CS, (5) RS mixed with $50 \%$ CS, and (6) $100 \%$ RS. Two experiments were executed and each of them was repeated twice ( 2 trials). Both experiments were conducted in randomized complete-blocks with four replicates. Each treatment was presented by five culture bags per replicate.

\section{Experiment I: composted rice straw formulations}

In this experiment, the raw rice straw (RRS) was used either sole or mixed with compost (CS) added at different percent portions $(5,10,15,25$, and $50 \%)$. Compost (CS) was made of moistened chopped RRS mixed with chicken manure and soil $(4: 1: 1, \mathrm{v} / \mathrm{v})$.

\section{Experiment II: composted corn straw formulations}

In this experiment, the raw corn straw (RCS) was used either sole or mixed with compost (CS) added at different percent portions $(5,10,15,25$, and $50 \%)$. Compost (CS) was made of moistened chopped RCS mixed with chicken manure and soil $(4: 1: 1, \mathrm{v} / \mathrm{v})$.

\section{General procedure}

\section{Preparation of composted substrate}

The chopped raw straw mixed with chicken manure and soil was piled up outdoors and moistened. The heap was kept for 2 weeks. Then, the pile was turned weekly to provide fresh air and prevent overheating. The composting continued under this process for 6 weeks. The mature compost was then used in preparation of the different substrate formulations.

\section{Preparation of substrate formulations and spawning}

The raw substrate was moistened thoroughly by soaking overnight in water. The raw and the composted substrates were pasteurized for $2 \mathrm{~h}$ in hot water at $80^{\circ} \mathrm{C}$ (Bahukhandi 
and Munjal 1989; Balasubramanya and Kathe 1996). The pasteurized substrate was left overnight (15-18 h) to cool down and to drain excess water. Subsequently, the raw substrate was thoroughly mixed with the corresponding composted substrate and checked to assure average moisture of about $70 \%$. The prepared substrate was manually packaged into $20 \times 40 \mathrm{~cm}$ clear polyethylene bags of mean thickness $0.2 \mathrm{~mm}$ containing $1-\mathrm{kg}$ moistened substrate. The spawn was inoculated at rate of $5 \%$ based on wet mass of the substrate.

\section{Culture conditions for spawn running and fruiting bodies formation}

The inoculated substrate was incubated for spawn running at $24-28{ }^{\circ} \mathrm{C}$ in the darkness for 3-4 weeks. The mushroom cultures were subsequently transferred into fruiting room for basidiocarp formation. Polyethylene bags were removed, and the cultures were kept at $22 \pm 1{ }^{\circ} \mathrm{C}$ under light provided by cool white fluorescent tubes for $12 \mathrm{~h} /$ day. Electric fans were used $4 \mathrm{~h} /$ day during incubation for basidiocarp formation to provide homogenous ventilation condition in the incubation room. The bags moisture was maintained by spraying with tap water two times a day during the whole cropping period. Mushroom fruiting bodies were harvested about a week after pinheads formation that was as soon as the gills were well formed, and while the edge of the caps is still curled under.

\section{Data records and statistical analysis}

Data were recorded for days lapsed to visible pinhead (primordia) formation, total fruiting bodies yield (overall flushes) (g) per $\mathrm{kg}$ moistened substrate, weight $(\mathrm{g})$ of mushroom spent substrate, biological efficiency (\%), average fruiting body weight $(\mathrm{g})$, diameter $(\mathrm{mm})$ and thickness $(\mathrm{mm})$ and average stem weight $(\mathrm{g})$, diameter $(\mathrm{mm})$, and length $(\mathrm{cm})$. Biological efficiency $(\mathrm{BE})$ was calculated as follows: BE $(\%)=$ (weight of fresh mushroom fruiting bodies/weight of dry substrate $) \times 100$ (Ahmed 1995; Kirbag and Akyüz 2008). All data were subjected to analysis of variance (Gomez and Gomez 1984), and the means were compared using "the least significant difference" (LSD) test at 0.05 probability level.

\section{Results}

Both rice and corn substrate formulations containing 50, 75 , and $100 \%$ composted straw (CS) showed no mushroom colonization and, subsequently, no fruiting bodies formation in the pilot assessment. Meanwhile, mushroom fungus spawn running and fructification were observed on the sole raw rice straw (RRS) and sole raw corn straw (RCS) substrates in this assessment.

\section{Experiment I: composted rice straw formulations}

Fruit bodies yield of Pleurotus columbinus mushroom grown on raw rice straw (RRS) mixed with 5 or $10 \%$ composted straw (CS), in contrast to sole RRS substrate, exhibited significant increase in the first trial but not in the second one (Table 1a). When grown on substrate formulation containing $25 \% \mathrm{CS}$, mushroom showed tendency to produce lower yield in the first trial, while significant reduction was detected in fruiting bodies yield in the second trial. Consistently, mushroom grown on substrate formulation containing $15 \%$ CS produced fruiting bodies yield significantly surpassing all the other treatments in the first trial, but except substrate formulation containing $10 \%$ $\mathrm{CS}$ in the second trial. Again in both trials, there were no fruiting bodies produced when the fungus was grown on rice substrate formulation containing $50 \%$ CS (negative control treatment). Data obtained for spent weight substantiated those of the fruiting bodies yield (Table 1a). Spent weight was the least for mushroom grown on the substrate formulation composed of $85 \%$ RRS and $15 \%$ CS. Thus, the fungus consumed larger amount of components of this substrate formulation. Mushroom grown on formulation containing $5 \%$ CS utilized greater amount of the substrate than that one grown on RRS (positive control treatment). Meanwhile, greater amount of the substrate formulation containing $10 \% \mathrm{CS}$ was utilized by the fungus than that one containing $5 \%$ CS. However, the utilized quantity of the substrate formulation containing $25 \%$ did not differ from that of the RRS (positive control). Apparently, the substrate formulation containing $50 \%$ CS had the greatest spent weight.

Due to the highest fruiting bodies yield produced on the substrate formulation containing $15 \% \mathrm{CS}$, the fungus exhibited the highest biological efficiency for this formulation (Table 2a). The other substrate treatments, except $50 \%$ CS, showed inconsistence with regard to the significance of the difference in biological efficiency from the RRS substrate. Apparently, the substrate formulation containing $50 \% \mathrm{CS}$ was inferior to the RRS substrate regarding the biological efficiency. As a result of the superior capability for biodegradation of substrate having $15 \% \mathrm{CS}$, the fungus formed its pinheads exceptionally earlier than the others (Table 2a). Differently, the days lapsed to visible pinhead formation were similar for the mushroom grown on $0,5,10$, and $25 \%$. Obviously, the availability of nutrient components from the substrate for the mushroom grown on the formulation containing $15 \%$ $\mathrm{CM}$ enabled developing fruit bodies with caps of large diameter and great thickness and weight (Tables 3a, 4a). 
Table 1 Means of total fruiting bodies yield and spent weight for Pleurotus columbinus mushroom grown on raw rice straw (A) or raw corn straw (B) mixed with different percent portions of the corresponding composted straw

\begin{tabular}{|c|c|c|c|c|}
\hline \multirow[t]{2}{*}{ Compost portion $(\%)$} & \multicolumn{2}{|c|}{ Total fresh fruiting bodies yield (g/1 kg moistened substrate) } & \multicolumn{2}{|c|}{ Spent weight $(\mathrm{g})$} \\
\hline & 1st Trial & 2nd Trial & 1st Trial & 2nd Trial \\
\hline \multicolumn{5}{|l|}{ (A) Rice straw } \\
\hline 0 & 148.357 & 170.724 & 668.5 & 691.7 \\
\hline 5 & 175.661 & 171.136 & 466.7 & 504.7 \\
\hline 10 & 206.007 & 186.249 & 401.1 & 400.4 \\
\hline 15 & 248.169 & 201.923 & 267.1 & 246.1 \\
\hline 25 & 133.251 & 136.036 & 685.5 & 689.9 \\
\hline 50 & $0.000^{\mathrm{a}}$ & 0.000 & 776.5 & 817.6 \\
\hline $\operatorname{LSD}_{0.05}^{\mathrm{b}}$ & 19.732 & 18.065 & 33.7 & 49.6 \\
\hline \multicolumn{5}{|l|}{ (B) Corn straw } \\
\hline 0 & 126.039 & 115.081 & 766.5 & 831.5 \\
\hline 5 & 152.368 & 158.001 & 687.3 & 713.8 \\
\hline 10 & 158.128 & 168.289 & 506.3 & 587.7 \\
\hline 15 & 207.965 & 206.525 & 316.8 & 331.3 \\
\hline 25 & 119.325 & 108.250 & 770.2 & 735.3 \\
\hline 50 & $0.000^{\mathrm{a}}$ & 0.000 & 824.1 & 786.7 \\
\hline $\mathrm{LSD}_{0.05}^{\mathrm{b}}$ & 29.014 & 29.802 & 54.8 & 24.0 \\
\hline
\end{tabular}

Rice straw and corn straw were tested in separate experiments, and each experiment was repeated twice (two trials)

${ }^{\text {a }}$ No mushroom growth occurred

b The least significant difference at 0.05 level of probability to separate means of different compost portion treatments of the same experiment trial

Stems of the fruiting bodies for this treatment had increased weight, diameter, and length (Tables 4a, 5a).

\section{Experiment II: composted corn straw formulations}

Mushroom grown on raw corn straw (RCS) mixed with $5 \%$ composted straw (CS), in contrast to sole RCS substrate (positive control treatment), exhibited significantly higher fruiting bodies yield only in the second trial (Table 1b). The substrate formulation containing $10 \% \mathrm{CS}$ significantly elevated fruiting bodies yield in both trials. Fruiting bodies yield was similar whether the mushroom was grown on substrate formulation containing $25 \% \mathrm{CS}$ or sole raw corn straw (RCS) substrate. Consistently, mushroom grown on substrate formulation containing $15 \% \mathrm{CS}$ produced fruiting bodies yield significantly surpassing all the other treatments. There were no fruiting bodies produced in both trials when the fungus was grown on corn substrate formulation containing $50 \%$ CS (negative control treatment). The least spent weight was for mushroom grown on the substrate formulation contained $15 \% \mathrm{CS}$ (Table 1b). The fungus, therefore, degraded and consumed larger amount of components from this substrate formulation than any other substrates. Mushroom grown on formulation containing $5 \% \mathrm{CS}$ utilized greater amount of the substrate components than the one grown on RCS (positive control treatment). Meanwhile, greater components amount of the substrate formulation containing $10 \% \mathrm{CS}$ was utilized by the fungus than that one containing $5 \% \mathrm{CS}$. The utilized quantity of the substrate formulation containing $25 \%$ was significantly less than RCS (positive control) only in the second trial.

Due to the highest biodegradation occurred for the substrate formulation containing $15 \% \mathrm{CS}$, the mushroom exhibited the highest biological efficiency (Table $2 \mathrm{~b}$ ). The other substrate formulations, except those containing 25 and $50 \% \mathrm{CS}$, showed significantly higher biological efficiency than RCS substrate. In both trials, the substrate formulation containing 25 or $50 \% \mathrm{CS}$ did not differ from RCS substrate regarding the biological efficiency. As a result of the superior capability for biodegradation of substrate having $15 \% \mathrm{CS}$, the fungus formed its pinheads exceptionally earlier than the others (Table 2b). Contrary to this result, the days lapsed to visible pinhead formation increased for the mushroom grown on RCS mixed with $25 \% \mathrm{CS}$. On the other hand, significantly earlier visible pinhead formation was detected for cultures on RCS containing 5 and $10 \% \mathrm{CS}$ than sole RCS. Noticeably, the availability of nutrient components from the substrate for the mushroom grown on the formulation containing $15 \%$ 
Table 2 Means of biological efficiency and days lapsed to visible pinheads (primordia) formation for Pleurotus columbinus mushroom grown on raw rice straw (A) or raw corn straw (B) mixed with different percent portions of the corresponding composted straw

\begin{tabular}{|c|c|c|c|c|}
\hline \multirow[t]{2}{*}{ Compost portion $(\%)$} & \multicolumn{2}{|c|}{ Biological efficiency (\%) } & \multicolumn{2}{|c|}{ Days lapsed to visible pinheads (primordia) formation } \\
\hline & 1st Trial & 2nd Trial & 1st Trial & 2nd Trial \\
\hline \multicolumn{5}{|l|}{ (A) Rice straw } \\
\hline 0 & 59.3 & 68.3 & 34.5 & 34.5 \\
\hline 5 & 70.3 & 68.5 & 34.3 & 34.3 \\
\hline 10 & 82.4 & 74.5 & 34.2 & 35.2 \\
\hline 15 & 99.3 & 80.8 & 29.6 & 29.8 \\
\hline 25 & 53.3 & 54.4 & 34.6 & 35.4 \\
\hline 50 & $0.0^{\mathrm{a}}$ & 0.0 & 0.0 & 0.0 \\
\hline $\mathrm{LSD}_{0.05}^{\mathrm{b}}$ & 7.9 & 7.2 & 0.4 & 1.2 \\
\hline \multicolumn{5}{|l|}{ (B) Corn straw } \\
\hline 0 & 50.4 & 46.0 & 39.3 & 39.7 \\
\hline 5 & 68.9 & 63.2 & 37.5 & 37.5 \\
\hline 10 & 63.2 & 67.3 & 37.2 & 38.3 \\
\hline 15 & 83.2 & 82.6 & 30.3 & 31.1 \\
\hline 25 & 47.7 & 43.3 & 41.3 & 41.6 \\
\hline 50 & $0.0^{\mathrm{a}}$ & 0.0 & 0.0 & 0.0 \\
\hline $\mathrm{LSD}_{0.05}^{\mathrm{b}}$ & 11.6 & 11.9 & 1.6 & 1.2 \\
\hline
\end{tabular}

Rice straw and corn straw were tested in separate experiments, and each experiment was repeated twice (two trials)

${ }^{\text {a }}$ No mushroom growth occurred

b The least significant difference at 0.05 level of probability to separate means of different compost portion treatments of the same experiment trial

CM enabled developing fruit bodies with caps of largest diameter and greatest thickness and weight (Tables $3 b, 4 b$ ). Greatest weight, diameter, and length (Tables $4 \mathrm{~b}, 5 \mathrm{~b}$ ) were found for stems of the mushroom fruiting bodies produced by the substrate formulation containing $15 \% \mathrm{CS}$.

\section{Discussion}

The main components of the lignocellulosic substrates are cellulose, hemi-cellulose, and lignin. Pleurotus mushrooms can biodegrade cellulose and lignin of lignocellulosic materials to get their carbon requirements. However, Pleurotus mushrooms also need nitrogen and inorganic compounds. The substrate material utilized alone for cultivation of Pleurotus mushrooms sometimes cannot provide enough nitrogen and/or other nutrients required for optimal growth (Siqueira et al. 2012; Soliman 2011; Soliman et al. 2011). Therefore, supplements, such as rice and wheat bran, are added as a nitrogen source (Jafarpour and Eghbalsaeed 2012; Soliman 2011). In this regard, composting converts the components of raw lignocellulosic materials into a superior nutritional source especially protein for mushroom (Rajarathnam and Bano 1989) through the actions of a succession of microorganisms. However, total nitrogen should not exceed the amount from which the ammonia nitrogen created during fermentation can restrain the mycelial growth of the mushroom (Choi 2004). For the cultivation of Pleurotus spp., the compost containing $0.6-0.9 \% \mathrm{~N}$ of its dry weight, depending on the species, is recommended (Imbernoon et al. 1983; Laborde 1987).

Noticeably, there was a significant progressive upgrading in this study for growth and crop outcome with increasing the percentage of composted straw materials mixed with the raw substrate up to $15 \%$. Utilizing the composted materials at $25 \%$ apparently downgraded these parameters. No mushroom growth was observed at all when cultivated in medium contained $50 \%$ or more of composted straw materials. Instead, molds of different colors grown on this latter substrate mixture. Unlike the end up result of our study, composted straw materials can be utilized entirely as substrate for cultivation of oyster mushroom, and it has been found to definitely improve yield and quality of oyster mushroom crop outcome (Choi 2004). In the method used by Choi (2004), raw substrate without supplements was moistened and left for composting by microorganisms naturally subsist on the surface of the dry raw substrate.

Here, we prepared the composted materials from rice or corn straw mixed with chicken droppings. Diminutive 
Table 3 Average diameter and thickness of fruiting body cap for Pleurotus columbinus mushroom grown on raw rice straw (A) or raw corn straw (B) mixed with different percent portions of the corresponding composted straw

\begin{tabular}{|c|c|c|c|c|}
\hline \multirow[t]{2}{*}{ Compost portion $(\%)$} & \multicolumn{2}{|c|}{ Average diameter of fruiting body cap (mm) } & \multicolumn{2}{|c|}{ Average thickness of fruiting body cap (mm) } \\
\hline & 1st Trial & 2nd Trial & 1st Trial & 2nd Trial \\
\hline \multicolumn{5}{|l|}{ (A) Rice straw } \\
\hline 0 & 86.8 & 91.5 & 7.3 & 8.3 \\
\hline 5 & 102.8 & 99.3 & 8.8 & 9.0 \\
\hline 10 & 115.3 & 116.5 & 8.9 & 9.8 \\
\hline 15 & 136.8 & 130.8 & 14.7 & 13.7 \\
\hline 25 & 92.5 & 85.0 & 7.6 & 8.1 \\
\hline 50 & $0.0^{\mathrm{a}}$ & 0.0 & 0.0 & 0.0 \\
\hline $\operatorname{LSD}_{0.05}^{\mathrm{b}}$ & 5.1 & 8.9 & 2.3 & 1.7 \\
\hline \multicolumn{5}{|l|}{ (B) Corn straw } \\
\hline 0 & 104.1 & 107.2 & 8.1 & 7.9 \\
\hline 5 & 108.9 & 112.2 & 8.5 & 7.9 \\
\hline 10 & 118.3 & 121.8 & 10.1 & 9.1 \\
\hline 15 & 145.2 & 146.7 & 12.5 & 11.5 \\
\hline 25 & 96.0 & 98.9 & 5.4 & 5.0 \\
\hline 50 & $0.0^{\mathrm{a}}$ & 0.0 & 0.0 & 0.0 \\
\hline $\mathrm{LSD}_{0.05}^{\mathrm{b}}$ & 6.2 & 5.2 & 2.4 & 2.3 \\
\hline
\end{tabular}

Rice straw and corn straw were tested in separate experiments, and each experiment was repeated twice (two trials)

${ }^{\text {a }}$ No mushroom growth occurred

b The least significant difference at 0.05 level of probability to separate means of different compost portion treatments of the same experiment trial

Table 4 Average weight of fruiting body cap and stem for Pleurotus columbinus mushroom grown on raw rice straw (A) or raw corn straw (B) mixed with different percent portions of the corresponding composted straw

\begin{tabular}{|c|c|c|c|c|}
\hline \multirow[t]{2}{*}{ Compost portion (\%) } & \multicolumn{2}{|c|}{ Average weight of fruiting body cap $(\mathrm{g})$} & \multicolumn{2}{|c|}{ Average weight of stem $(\mathrm{g})$} \\
\hline & 1st Trial & 2nd Trial & 1st Trial & 2nd Trial \\
\hline \multicolumn{5}{|l|}{ (A) Rice straw } \\
\hline 0 & 7.318 & 7.603 & 2.905 & 3.025 \\
\hline 5 & 7.728 & 8.504 & 3.255 & 3.227 \\
\hline 10 & 8.761 & 9.061 & 3.387 & 3.622 \\
\hline 15 & 9.853 & 9.625 & 3.975 & 3.932 \\
\hline 25 & 7.172 & 7.352 & 2.988 & 3.037 \\
\hline 50 & $0.0^{\mathrm{a}}$ & 0.0 & 0.0 & 0.0 \\
\hline $\mathrm{LSD}_{0.05}^{\mathrm{b}}$ & 1.340 & 1.455 & 0.141 & 0.132 \\
\hline \multicolumn{5}{|l|}{ (B) Corn straw } \\
\hline 0 & 7.303 & 7.174 & 4.042 & 3.188 \\
\hline 5 & 9.555 & 9.266 & 4.263 & 3.417 \\
\hline 10 & 9.890 & 9.537 & 5.033 & 4.321 \\
\hline 15 & 12.328 & 11.968 & 6.667 & 5.517 \\
\hline 25 & 7.353 & 6.838 & 4.554 & 3.808 \\
\hline 50 & $0.000^{\mathrm{a}}$ & 0.000 & 0.000 & 0.000 \\
\hline $\mathrm{LSD}_{0.05}^{\mathrm{b}}$ & 0.447 & 0.434 & 0.582 & 0.544 \\
\hline
\end{tabular}

Rice straw and corn straw were tested in separate experiments, and each experiment was repeated twice (two trials)

${ }^{a}$ No mushroom growth occurred

b The least significant difference at 0.05 level of probability to separate means of different compost portion treatments of the same experiment trial 
Table 5 Average stem length and diameter for Pleurotus columbinus mushroom grown on raw rice straw (A) or raw corn straw (B) mixed with different percent portions of the corresponding composted straw

\begin{tabular}{|c|c|c|c|c|}
\hline \multirow[t]{2}{*}{ Compost portion (\%) } & \multicolumn{2}{|c|}{ Average length of stem $(\mathrm{cm})$} & \multicolumn{2}{|c|}{ Average stem diameter $(\mathrm{mm})$} \\
\hline & 1st Trial & 2nd Trial & 1st Trial & 2nd Trial \\
\hline \multicolumn{5}{|l|}{ (A) Rice straw } \\
\hline 0 & 2.5 & 2.5 & 7.3 & 9.9 \\
\hline 5 & 2.8 & 2.8 & 8.6 & 12.1 \\
\hline 10 & 3.1 & 3.3 & 9.9 & 14.2 \\
\hline 15 & 4.1 & 4.2 & 14.0 & 15.7 \\
\hline 25 & 2.5 & 2.5 & 9.9 & 10.5 \\
\hline 50 & $0.0^{\mathrm{a}}$ & 0.0 & 0.0 & 0.0 \\
\hline $\mathrm{LSD}_{0.05}^{\mathrm{b}}$ & 0.2 & 0.2 & 4.7 & 2.4 \\
\hline \multicolumn{5}{|l|}{ (B) Corn straw } \\
\hline 0 & 3.2 & 3.0 & 8.5 & 8.3 \\
\hline 5 & 3.5 & 3.4 & 10.9 & 11.3 \\
\hline 10 & 3.8 & 3.7 & 12.5 & 11.9 \\
\hline 15 & 6.0 & 5.4 & 23.5 & 25.2 \\
\hline 25 & 3.3 & 3.0 & 10.0 & 10.1 \\
\hline 50 & $0.0^{\mathrm{a}}$ & 0.0 & 0.0 & 0.0 \\
\hline $\mathrm{LSD}_{0.05}^{\mathrm{b}}$ & 0.4 & 0.2 & 1.2 & 1.3 \\
\hline
\end{tabular}

Rice straw and corn straw were tested in separate experiments, and each experiment was repeated twice (two trials)

${ }^{\text {a }}$ No mushroom growth occurred

b The least significant difference at 0.05 level of probability to separate means of different compost portion treatments of the same experiment trial information has been reported on use of chicken manure supplement to substrates in production of mushroom. As reported by Baysal et al. (2003), increased supplement of chicken manure to waste paper substrate had a negative effect on growing mushroom. Oyster mushroom yield decreases when the ammonia resulting from conversion of nitrogen during fermentation process is higher than $68 \mathrm{ppm}$ as well as when total nitrogen is smaller than the optimal amount (Choi 2004). The chicken manure is rich in nitrogen in addition to phosphorus, potassium and calcium. It is suggested that the used compost here may have high total $\mathrm{N}$. Mixing the composted straw materials at certain portions with raw substrate could have adjusted the total $\mathrm{N}$ to a suitable level for mushroom growth. In this study, the formulation composed of raw rice straw or raw corn straw mixed with $15 \%$ composted straw materials showed superiority.

The microorganism species that may compete with Pleurotus spp. after pasteurization with hot water $\left(80{ }^{\circ} \mathrm{C}\right.$ for $2 \mathrm{~h}$ ) includes the fungi Penicillium spp. and Trichoderma spp. (green mold) (Balasubramanya and Kathe 1996). Pasteurization at high temperatures could make cellulose more available (Sturion and Oetterer 1995), due to the partial destruction of the lignin-cellulose bonds. Partial breakdown of cellulose and hemi-cellulose make them available to competitor microorganisms. We conducted pasteurization at $80{ }^{\circ} \mathrm{C}$, and this in conjunction with the lack of competition due to restrained mushroom growth on medium formulation contained $50 \%$ or more composted straw materials can be accounted for the molds contamination observed.

This study, therefore, supports the notion of magnificent impact of substrate preparation on Pleurotus mushroom productivity. The biological efficiency enhanced relative to the sole raw substrate. The fruiting bodies crop outcome exhibited up to $80 \%$ increase, relative to sole raw straws, when the mushroom was grown on substrate formulation containing $15 \%$ composted straw material. The improved fruiting bodies yield was accompanied with magnificently enhanced weight and size for the harvested fruit caps. This substrate formulation produced mushroom crop earlier by 5-9 days, on average, than the cultivation on sole raw straws.

\section{Conclusion}

Composting may hold a promise for developing Pleurotus mushroom production industry. Under the conditions of this study, a formulation of mixed composted straw with raw rice straw or raw corn straw at rate of $15 \%$ is proposed. 
Acknowledgments The authors would like to express appreciation to the Higher Administration of Faculty of Agriculture, Assiut University for the financial support to conduct this study in the mushroom research and production lab.

Open Access This article is distributed under the terms of the Creative Commons Attribution 4.0 International License (http://crea tivecommons.org/licenses/by/4.0/), which permits unrestricted use, distribution, and reproduction in any medium, provided you give appropriate credit to the original author(s) and the source, provide a link to the Creative Commons license, and indicate if changes were made.

\section{References}

Ahmed AA (1995) Scientific mushrooms encyclopedia: Mushroom cultivation (2). Arab House for Publishing and Distribution, p 248 (In Arabic)

Bahukhandi D, Munjal RL (1989) Cultivation of Pleurotus species on different agricultural residues. Indian Phytopathol 42:492-495

Balasubramanya RH, Kathe AA (1996) An inexpensive pretreatment of cellulosic materials for growing edible oyster mushrooms. Bioresour Technol 57:303-305

Baysal E, Peker H, Yalinkilic MK, Temiz A (2003) Cultivation of oyster mushroom on waste paper with some added supplementary materials. Bioresource Technol. 89:95-97

Choi KW (2004) Shelf cultivation of oyster mushroom with emphasis on substrate fermentation, In: Rick Gush (ed) Mushroom Growers Handbook 1. Part II Oyster Mushroom, Aloha Medicinals Inc., Hawaii

Choi U, VK Bajpai, Lee N (2009) Influence of calcinated starfish powder on growth, yield, spawn run and primordial germination of king oyster mushroom (Pleurotus eryngii). Food Chem Toxicol 47:2830-2833

Gomez KA, Gomez AA (1984) Statistical procedures for agricultural research, 2nd edn. John Wiley, NY

Imbernoon M, Brian C, Granit S (1983) New Strains of Pleurotus. Mushroom J. 124:117-123

Jafarpour M, Eghbalsaeed Sh (2012) High protein complementation with high fiber substrates for oyster mushroom cultures. Afr J Biotech 11:3284-3289

Jeznabadi EK, Jafarpour M, Eghbalsaied S (2016) King oyster mushroom production using various sources of agricultural wastes in Iran. Int J Recycl Org Waste Agric 5:17-24

Kirbag S, Akyüz M (2008) Evaluation of agricultural wastes for the cultivation of Pleurotus eryngii (DC. ex Fr.) Quel. var. ferulae Lanzi. African. J Biotech. 7(20):3660-3664

Laborde J (1987) Proposition Pour une Amelioration de la Culture Pleurote., P.H.M. Revue Hortic. 278:13-21

Lopes RX, Zied DC, Martos ET, Souza RJ, Silva R, Dias ES (2015) Application of spent Agaricus subrufescens compost in integrated production of seedlings and plants of tomato. Int J Recycl Org Waste Agric. 4:211-218
Mendez LA, Castro CAS, Casso RB, Leal CMC (2005) Effect of substrate and harvest on the amino acid profile of Oyster mushroom (Pleurotus ostreatus). J Food Compos Anal $18: 447-450$

Mohamed MF, Haridy AG, Aboul-Nasr MH, Soliman MM (2011) Prolonged water soaking for sawdust substrate and adding wheat bran enhance oyster mushroom productivity. Assiut J Agric Sci 42(5):66-84

Mohamed MF, Nassef DMT, Waly EA, Kotb AM (2012) Earliness, Biological efficiency and basidiocarp yield of Pleurotus ostreatus and $P$. columbinus oyster mushrooms in response to different sole and mixed substrates. Assiut J Agric Sci 43(4):91-114

Mohamed MF, Nassef DMT, Waly EA, Kotb AM (2014) Production of oyster mushroom (Pleurotus spp.) intercropped with field grown faba bean (Vicia faba L.) Asian. J Crop Sci 6(1):27-37

Obodai M, Johnson PNT (2002) The effect of nutrient supplements on the yield of pleurotus ostreatus mushroom grown on composted saw dust of Triplochiton scleroxylon. Tropical Sci 42(2):78-82

Rajarathnam S, Bano Z (1989) Pleurotus mushrooms: Part III. Biotransformations of natural lignocellulosic wastes: commercial applications and implications. Crit Rev Food Sci Nutr 28:31-113

Sarangi I, Ghosh D, Bhutia SK, Mallick SK, Maiti TK (2006) Antitumor and immunomodulating effects of Pleurotus ostreatus mycelia-derived proteoglycans. Int Immunopharmacol 6:1287-1297

Sher H, Al-Yemeni M, Bahkali AHA, Sher H (2010) Effect of environmental factors on the yield of selected mushroom species growing in two different agro ecological zones of Pakistan. Saudi J Biol Sci 17:321-326

Siqueira FG, Maciel WP, Martos ET, Duarte GC, Miller RNG, Silva R, Dias ES (2012) Cultivation of Pleurotus mushrooms in substrate obtained by short composting and steam pasteurization. African J Biotechnology 11(53):11630-11635

Soliman MM (2011) Influence of substrate mix and enrichment supplements on oyster mushroom growth and yield. M.Sc. Thesis, Assiut University, Egypt

Soliman MM, Mohamed MF, Aboul-Nasr MH, Haridy AG (2011) Influence of sucrose and blackstrap molasses supplemented to sawdust substrate on yield of oyster mushroom) Pleurotus ostreatus). Assiut J Agric Sci 42:424-433 (special issue, The 5th conf. Young Scientists, Faculty Agric, Assiut University, May 8th 2011)

Sturion GL, Oetterer MM (1995) Utilização da folha da bananeira como substrato para cultivo de cogumelos comestíveis (Pleurotus spp.). Ciência e Tecnologia de Alimentos 15:194-200

Valverde ME, Hernández-Pérez T, Paredes-López O (2015) Edible mushrooms: improving human health and promoting quality life. Int J Microbiol 2015(2015):376387. doi:10.1155/2015/376387

Zhang Y, Geng W, Shen Y, Wang Y, Dai YC (2014) Edible mushroom cultivation for food security and rural development in china: bio-innovation, technological dissemination and marketing. Sustainability 6:2961-2973 